\title{
Hydrogen bound water profiles in the skin influenced by optical clearing molecular agents- quantitative analysis using confocal Raman microscopy
}

\author{
Anton Yu. Sdobnov ${ }^{1,2, * \#, \text { Maxim E. Darvin }}{ }^{3, \#}$, Johannes Schleusener ${ }^{3}$, Jürgen Lademann ${ }^{3}$, \\ Valery V. Tuchin $2,4,5$ \\ \# These two authors contributed equally to this work \\ * Corresponding author: anton.sdobnov@oulu.fi
}

${ }^{1}$ Faculty of Information Technology and Electrical Engineering, University of Oulu, Oulu 90570, Finland

${ }^{2}$ Research-Educational Institute of Optics and Biophotonics, Saratov State University, Astrakhanskaya 83, 410012 Saratov, Russian Federation

${ }^{3}$ Center of Experimental and Applied Cutaneous Physiology, Department of Dermatology, Venerology and Allergology, Charité - Universitätsmedizin Berlin, Corporate member of Freie Universität Berlin, Humboldt-Universität zu Berlin, Berlin Institute of Health, Charitéplatz 1, 10117 Berlin, Germany

${ }^{4}$ Laboratory of Laser Diagnostics of Technical and Living Systems, Institute of Precision Mechanics and Control of RAS, Rabochaya 24, 410028 Saratov, Russian Federation

${ }^{5}$ Interdisciplinary Laboratory of Biophotonics, Tomsk State University, Lenin's av. 36, 634050 Tomsk, Russian Federation

Keywords: dermis, epidermis, skin barrier, glycerol, iohexol, Omnipaque ${ }^{\mathrm{TM}}$, Raman spectroscopy

Short title: A. Sdobnov et al.: Confocal Raman microscopy of hydrogen bound water profiles in the skin

\section{Abstract:}

Confocal Raman microscopy (CRM) has been used to measure depth-dependent profiles of porcine skin ex vivo in the high wavenumber region after application of molecular optical clearing agents (OCAs). Glycerol (70\%) and iohexol (100\% Omnipaque ${ }^{\mathrm{TM}}$ (300)) water solutions were used as OCAs and topically applied to porcine ear skin for 30 and $60 \mathrm{~min}$. Using Gaussian function-based deconvolution, the changes of hydrogen bound water molecule types have been microscopically analyzed down to the depth of $200 \mu \mathrm{m}$. Results show that both OCAs induced skin dehydration (reduction of total water), which is $51.3 \%$ for glycerol (60 $\mathrm{min}), 33.1 \%$ for glycerol $(30 \mathrm{~min}), 8.3 \%$ for Omnipaque ${ }^{\mathrm{TM}}(60 \mathrm{~min})$, and $4.4 \%$ for Omnipaque ${ }^{\mathrm{TM}}$ (30 min), on average for the 40-200 $\mu \mathrm{m}$ depths. Among the water types in This article has been accepted for publication and undergone full peer review but has not been through the copyediting, typesetting, pagination and proofreading process, which may lead to differences between this version and the Version of Record. Please cite this article as doi: $10.1002 /$ jbio.201800283 
the skin, the following reduction was observed in concentration of weakly bound $(51.1 \%$, $33.2 \%, 7.5 \%$, and $4.6 \%$ ), strongly bound $(50.4 \%, 33.0 \%, 7.9 \%$, and $3.4 \%)$, tightly bound $(63.6 \%, 42.3 \%, 26.1 \%$, and $12.9 \%)$ and unbound $(55.4 \%, 28.7 \%, 10.1 \%$, and $5.9 \%)$ water types on average for the $40-200 \mu \mathrm{m}$ depths, post application of glycerol (60 min), glycerol (30 min), Omnipaque ${ }^{\mathrm{TM}}$ (60 $\left.\mathrm{min}\right)$, and Omnipaque ${ }^{\mathrm{TM}}$ (30 min), respectively. As most concentrated in the skin, weakly and strongly bound water types are preferentially involved in the OCA-induced water flux in the skin, and thus, are responsible for optical clearing efficiency.

\section{Introduction}

The skin is the outer organ covering the body of the vertebrates. It is the largest multilayer organ of the human organism. Skin plays an important physiological function of barrier between the organism and environment, protecting the internal organs from external mechanical impact as well as from penetration of pathogens ${ }^{[1]}$. Further important skin functions are regulation of the water loss, insulation, thermo-regulation, etc. ${ }^{[2,3]}$. The stratum corneum (SC), the outer horny layer of the skin, serves as a first defense line ${ }^{[4]}$. It consists of corneocytes that are embedded in a matrix of intercellular lipids ${ }^{[5]}$, commonly referred to as a brick and mortar structure ${ }^{[6,7]}$. The lateral packing order of SC's intercellular lipids is primarily responsible for maintaining the skin barrier function ${ }^{[8,9]}$, which is distributed nonhomogeneously in the SC ${ }^{[10]}$. An early diagnosis of skin diseases, such as cancer, neurodermitis or psoriasis, and monitoring of disease treatment, delivery of drugs and cosmetics, as well as investigation of age-related skin structure alterations are urgent problems in dermatology and cosmetology. However, for precise diagnosis, an analysis of skin biopsies is still necessary. Since this is an invasive and painful procedure, the development of noninvasive methods for skin investigation became a promising and relevant field of research in the last few decades. 
Currently, a large amount of optical methods and techniques such as optical coherence tomography $(\mathrm{OCT})^{[11,12]}$, confocal Raman microscopy $(\mathrm{CRM})^{[4,13]}$, Raman and coherent anti-Stokes Raman spectroscopies (RS and CARS) ${ }^{[14-16]}$, laser scanning microscopy (LSM) ${ }^{[17]}$, multiphoton tomography (MPT) ${ }^{[18,19]}$, including CARS tomography ${ }^{[20,21]}$, laser speckle contrast imaging (LSCI) ${ }^{[22]}$, etc. have been implemented for noninvasive skin diagnostics in dermatology and cosmetology. However, all of these optical techniques have a critical limitation associated with the limited penetration depth caused by strong light scattering of the SC, living epidermis and dermis ${ }^{[23,24]}$.

In order to increase the probing depth, light focusing ability, spatial resolution of optical systems and image contrast, the optical clearing technique (OC), allowing for control of tissue optical properties, has been proposed. Fundamentals and advances of OC technologies for in vitro and in vivo applications were recently reviewed in a number of publications ${ }^{[25-31]}$. The influence of different optical clearing agents (OCAs), e.g. glycerol ${ }^{[32]}$, glucose ${ }^{[33,34]}$, dimethyl sulfoxide (DMSO) ${ }^{[35]}$, Scale ${ }^{[36]}$, Sca/eS ${ }^{[37]}$, PEG 400 and Thiazone ${ }^{[26]}$, was studied by various optical techniques such as $\mathrm{OCT}^{[38]}, \mathrm{MPT}^{[39,40]}, \mathrm{RS}^{[41]}, \mathrm{CRM}^{[42,43]}$, etc. ${ }^{[44]}$.

In general, three main mechanisms of OC have been suggested ${ }^{[45]}$. The first is matching of refractive indices caused by OCA diffusion into the tissue ${ }^{[46]}$. The second mechanism is associated with tissue dehydration induced by the OCA's hyperosmolarity ${ }^{[47,48]}$. The third is related to the reversible dissociation of collagen fibers caused by molecular interactions of exogenous chemical agents ${ }^{[49-51]}$. These and possibly other not yet discovered OC mechanisms usually work simultaneously with different relative contributions depending on tissue, OCA type and its concentration.

However, prolonged application of some high-concentrated OCAs were found to be toxic and destructive for the skin ${ }^{[52,53]}$. Also, OCA application can substantially influence the water content in the dermis ${ }^{[42]}$. As the hydration state and water bounding in the skin is of major 
interest in cosmetology and dermatology ${ }^{[54-56]}$, the search for the most effective, low-cost, and at the same time, non-destructive and non-toxic OCAs with controllable influence on the skin water content for clinical application became a hot topic in the last few years ${ }^{[57-60]}$. In this context it is necessary to differentiate water control in skin layers on the short (minutes) and long (hours and days) time scales. For effective OC it is possible to provide fast, strong and reversible skin dehydration for tissue in-depth laser probing aiming at diagnostics, therapy or theranostics ${ }^{[24,26,45,46,61-65]}$. This can be done by using highly concentrated OCAs together with enhancers of skin permeability ${ }^{[24,26,45,46]}$. Similar agents, such as glycerol, at low concentrations serve on a long time scale as major components of skin prolonged hydration lotions ${ }^{[60]}$.

Glycerol is one of the most commonly used OCAs due to its biocompatibility and pharmacokinetics ${ }^{[66]}$. The difference between biological membrane permeability for glycerol and water leads to skin dehydration ${ }^{[48]}$. As a result, the reduced water content in the interstitial space and in the cells improves the refractive index matching, allowing for deeper probing depths. Iohexol (tradename Omnipaque ${ }^{\mathrm{TM}}$ ) belongs to the latest generation of $\mathrm{x}$-ray non-ionic isotonic contrasting agents ${ }^{[67,68]}$. Omnipaque ${ }^{\mathrm{TM}}(300)$ has been proven to be an effective agent for porcine skin OC during previous ex vivo measurements using MPT ${ }^{[40]}$ and $\mathrm{CRM}^{[42]}$. Also, this OCA has been successfully used for OCT ${ }^{[67]}$ and LSCI $^{[69]}$ measurements.

RS and CRM have been widely used in skin research for clinical and cosmetic purposes ${ }^{[15,70-}$ ${ }^{76]}$ within the last decade. RS/CRM are fully automated and easy to perform techniques allowing to distinguish structural and molecular changes of the tissue with high sensitivity and spatial resolution, as e.g. to determine the penetration depth of topically applied substances ${ }^{[13 \text {, }}$ 32, 75, 77-79] . Caspers et al. ${ }^{[80]}$ presented a method for depth-resolved calculation of the water mass concentration profile, based on the intensity ratio between the Raman band of water (3350-3550 $\left.\mathrm{cm}^{-1}\right)$ and proteins (2910-2965 $\left.\mathrm{cm}^{-1}\right)$. Nikagawa et al. ${ }^{[81]}$ demonstrated that the 
dermal water content can be measured in vivo up to $200 \mu \mathrm{m}$ using CRM and identical normalization on proteins. Vyumvuhore et al. ${ }^{[82]}$ showed that the different types of water molecules (primary bound water, partially bound water and unbound water) could be evaluated in the extracted SC using Gaussian function-based deconvolution of the Raman $\mathrm{OH}$ band in the range from $3100 \mathrm{~cm}^{-1}$ to $3700 \mathrm{~cm}^{-1}$. Recently, for the first time, Choe et al. ${ }^{[83]}$ demonstrated the distribution of different water types in the human SC in vivo. The authors have shown that strongly hydrogen bound water (double donor-double acceptor, DDAA-OH) and weakly hydrogen bound water (single donor-single acceptor, DA-OH) represent more than $90 \%$ of the entire SC's water content, while tightly hydrogen bound water (single donordouble acceptor, DAA) and free water molecule types represent the remaining $<10 \%$.

In the present study, the influence of OC on the depth-dependent profile of different water molecule types of porcine skin are investigated ex vivo, based on the deconvolution method proposed in the literature ${ }^{[82,84]}$ and adapted by Choe et al. ${ }^{[83]}$, to the depth of $200 \mu \mathrm{m}$, i.e., to the reticular dermis.

\section{Materials and Methods}

\subsection{Skin samples}

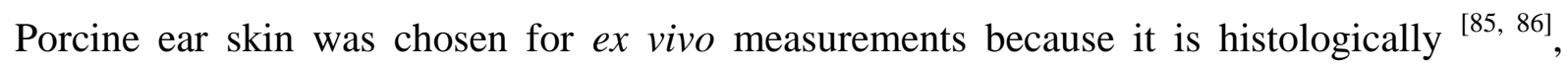
morphologically ${ }^{[87]}$ and immunohistochemically ${ }^{[88]}$ similar to the human skin. However, in spite of these similarities, porcine SC ex vivo is characterized by a reduced skin barrier function compared to human SC in vivo, which was recently determined using CRM ${ }^{[89]}$. The porcine ear skin was delivered to the laboratory on the day of sacrifice from a local butcher (Gerald Nusche Rind-/Schweineschlachterei, Königs Wusterhausen, Germany), cleansed with cold running water and dried using a paper towel. Eight different ears were investigated during the experiment. Five skin samples with $1 \times 1 \mathrm{~cm}^{2}$ size and approx. $1.2 \mathrm{~mm}$ thickness 
were manually sliced from every porcine ear with a scalpel and stored in a refrigerator at a temperature of $+5{ }^{\circ} \mathrm{C}$ no longer than 2 days. In preparation of the experiment, the skin samples were left for $30 \mathrm{~min}$ at a room temperature of $20 \pm 1{ }^{\circ} \mathrm{C}$. For better penetration of OCAs into the skin, the hair was gently removed from the skin by shaving, as well as 20 tapes were successively pressed onto the skin and removed part of the SC, respectively, by the tape stripping method. Then, the skin surface was defatted using ethanol. Finally, these skin samples with reduced barrier were placed in a Petri dishes filled with different OCAs for 30 and $60 \mathrm{~min}$. Each porcine ear skin sample, which served as control (untreated skin sample), has been identically shaved, tape stripped and defatted. For each sample, at least five different spots on the skin areas were chosen for investigation using CRM. It is important to note that despite the fact that both, epidermal and dermal sides of the samples were in contact with the OCAs, the interaction time of 60 min was not sufficient for the OCAs to penetrate through all skin layers from the dermal and epidermal sides ${ }^{[40,46]}$. Thus, no direct penetration of OCAs from the dermal region could be detected at the investigated depths. As far as prolonged application can cause a negative effect on skin. It is important to investigate the OC effect and ,OCAs' influence on the skin water content at different time intervals and depths with the main aim to find the fastest penetrating and safest OCA for in vivo clinical application.

Approval for the experiments had been obtained from the Veterinary Board, District of Berlin Treptow-Köpenick, Germany.

\subsection{Optical clearing agents (OCAs)}

For the investigation of the optical clearing effect, glycerol and Omnipaque ${ }^{\mathrm{TM}}$ (300) were chosen. Glycerol was proven as an effective OCA for application to the skin ${ }^{[90,91]}$. The $70 \%$ glycerol solution in distilled water (v/v) was found to be optimal for $\mathrm{OC}^{[40,92]}$ and therefore was used in this study. This solution is characterized by the refractive index $n=1.428$, 
viscosity $22.5 \mathrm{cp}$ and osmolarity $9.62 \mathrm{Osm} / \mathrm{L}$ at $20{ }^{\circ} \mathrm{C}{ }^{[93]}$. Omnipaque ${ }^{\mathrm{TM}}$ (300), originally designed as image contrasting agents for x-ray computer tomography, was chosen as a second OCA in this study. As $100 \%$ Omnipaque $^{\mathrm{TM}}$ (300) was found to be optimal ${ }^{[40]}$ for OC, pure Omnipaque $^{\mathrm{TM}}$ (300) has been chosen in this study. This agent has a refractive index of $n=1.432$, viscosity of $11.8 \mathrm{cp}$ and osmolarity of $0.465 \mathrm{Osm} / \mathrm{L}$ at $20{ }^{\circ} \mathrm{C}^{[40,94]}$.

\subsection{Confocal Raman microscopy (CRM)}

The CRM measurements were performed using a skin composition analyzer appropriate for in vivo/ex vivo skin measurements (RiverD International B.V., Model 3510 SCA, Rotterdam, The Netherlands). The following settings were used to analyze skin in the high wavenumber (HWN) region (2000-4000 $\left.\mathrm{cm}^{-1}\right)$ : excitation wavelength of $671 \mathrm{~nm}$, oil objective of $\times 50$ magnification with a spot size of $\leq 5 \mu \mathrm{m}$, laser power of $19 \mathrm{~mW}$ on the skin surface and an exposure time of $1 \mathrm{~s}$. For the determination of the skin surface position, the following settings were used: excitation wavelength of $785 \mathrm{~nm}$ for the fingerprint region $\left(400-2000 \mathrm{~cm}^{-1}\right)$, laser power of $20 \mathrm{~mW}$ on the skin surface and an exposure time of $5 \mathrm{~s}$. The spatial resolution of the instrument was $\leq 5 \mu \mathrm{m}$, and the spectral resolution was $2 \mathrm{~cm}^{-1}$. The utilized doses of reference light were below the safety limit and did not influence the skin components due to the reported generation of free radicals ${ }^{[95,96]}$ and the local temperature increase ${ }^{[97]}$. The utilized CRM system was described in detail elsewhere ${ }^{[73]}$.

\subsection{Data analysis}

For investigation of the OC effect, skin samples from the eight porcine ears were immersed in different OCA solutions for 30 and $60 \mathrm{~min}$. Subsequently, the OCA solutions were gently removed from the sample surface using a paper towel before acquiring the spectra. The Raman spectra were recorded from the skin surface down to a depth of $200 \mu \mathrm{m}$ at $40 \mu \mathrm{m}$ increments of the immersed skin and untreated control skin. At least 5 different spots on each 
sample have been analyzed, i.e. 40 depth profiles were collected each for untreated and OCAtreated skin. After obtaining the Raman spectral profiles, the data for each ear were averaged. Data processing was performed using MatLab R2017b software (MathWorks, Natick, MA, USA).

The low variability components of the Raman spectra in the HWN range were classified as noise and were therefore filtered using principal component analysis ${ }^{[10,78]}$. In order to do so, the first 4 principal components were used to reconstruct the Raman spectra.

The skin surface position was determined using the method described in ${ }^{[78,98]}$. The strong Raman peak of Omnipaque ${ }^{\mathrm{TM}}$ centered at $1650 \mathrm{~cm}^{-1}$ prevented the skin surface determination by tracking the keratin concentration as described in ${ }^{[42]}$. Thus, the skin surface position was evaluated by calculating the area under the curve (AUC) of the phenylalanine/urea Raman peak in the range from 998 to $1008 \mathrm{~cm}^{-1}$. The skin surface position was determined as the half between the minimum and maximum AUC values.

As far as Raman spectra of the molecular vibrations are overlaid by fluorescence of the skin, the baseline removal procedure was performed using the method proposed by Choe et al. ${ }^{[83]}$. After baseline removal, the deconvolution procedure of the porcine skin Raman peaks in the HWN region (2770-3900 $\mathrm{cm}^{-1}$ ) was performed using 10 Gaussian functions (see Figure 1). For each investigated depth, 4 Gaussian functions centered at around $\left( \pm 5 \mathrm{~cm}^{-1}\right) 2850,2880$, 2930 and $2980 \mathrm{~cm}^{-1}$ have been assigned to model the lipid-keratin band $\left(2820-3030 \mathrm{~cm}^{-1}\right)$. The spectral range of $3000-3800 \mathrm{~cm}^{-1}$, representing the $\mathrm{OH}$ vibration of water with low contribution of proteins, was deconvolved using 6 Gaussian functions. The AUCs of the 4 water-related Gaussian functions centered around $\left( \pm 5 \mathrm{~cm}^{-1}\right) 3005,3277,3458$ and $3604 \mathrm{~cm}^{-1}$, which correspond to tightly hydrogen bound water molecules (DAA-OH, single donordouble acceptor), strongly hydrogen bound water (DDAA-OH, double donor-double acceptor), weakly hydrogen bound water (DA-OH, single donor-single acceptor) and free water (superposition of very weakly bound water type DDA-OH, double donor-single 
acceptor and unbound $\mathrm{OH})^{[83]}$, were calculated. Also, 2 Gaussian functions centered at around $\left( \pm 5 \mathrm{~cm}^{-1}\right) 3060$ and $3330 \mathrm{~cm}^{-1}$ have been chosen to model the unsaturated methylene stretching band of proteins and NH vibration band of proteins, respectively. The width of each Gaussian function in different skin depths was allowed to vary within $10 \mathrm{~cm}^{-1}$ to provide better fitting quality.

The total water content was calculated as a ratio of the sum of the AUCs of all 4 hydrogen bound water types to the protein content (AUC of the Gaussian function centered at 2930 $\left.\mathrm{cm}^{-1}\right)$.

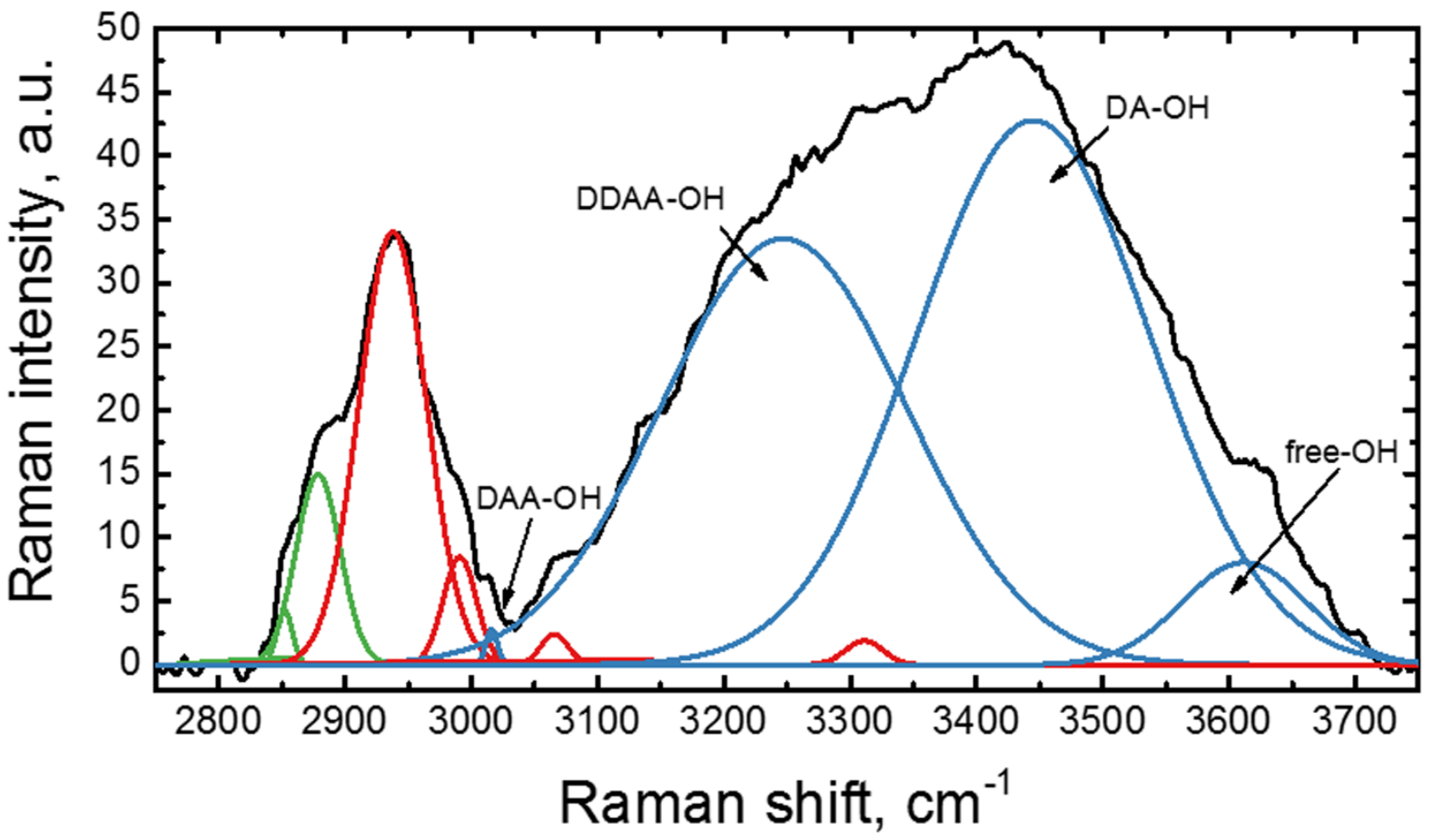

Figure 1. Gaussian function-based deconvolution procedure of the porcine skin (depth 80  $\mathrm{OH}, \mathrm{DA}-\mathrm{OH}$, and free-OH water types).

\subsection{Statistical analysis}

The statistical evaluation was performed using the Matlab statistics toolbox (The MathWorks, Natick, MA, USA). To confirm whether there was a statistical difference between the mean values of OCA treated and untreated skin samples, the paired Student's $t$-test was applied. 
Then, the Bonferroni correction method has been implemented to determinate significant differences $p<0.005$ (denoted as “*”).

\section{Results and Discussion}

Figure 2 shows the Raman spectra in the fingerprint (a) and HWN (b) regions for the Omnipaque $^{\mathrm{TM}}$ and glycerol solutions. It can clearly be seen that in the HWN region both agents have a signal in the $3100-3700 \mathrm{~cm}^{-1}(\mathrm{CO}-\mathrm{H}$ and $\mathrm{OH}$ vibrations of OCAs) and in the 2910-2965 $\mathrm{cm}^{-1}\left(\mathrm{CH}_{2}\right.$ vibrations of OCAs) ${ }^{[99]}$, which are superimposed with water and protein Raman peaks of the skin. Previous results showed that at the same study conditions, Omnipaque $^{\mathrm{TM}}$ penetrates up to $35-40 \mu \mathrm{m}$ depth into porcine skin within $60 \mathrm{~min}$ treatment, while glycerol reaches to the depth of $160 \mu \mathrm{m}^{[42]}$. Therefore, OCA's own Raman peaks in the HWN region can possibly affect results of the spectral analysis of the skin.
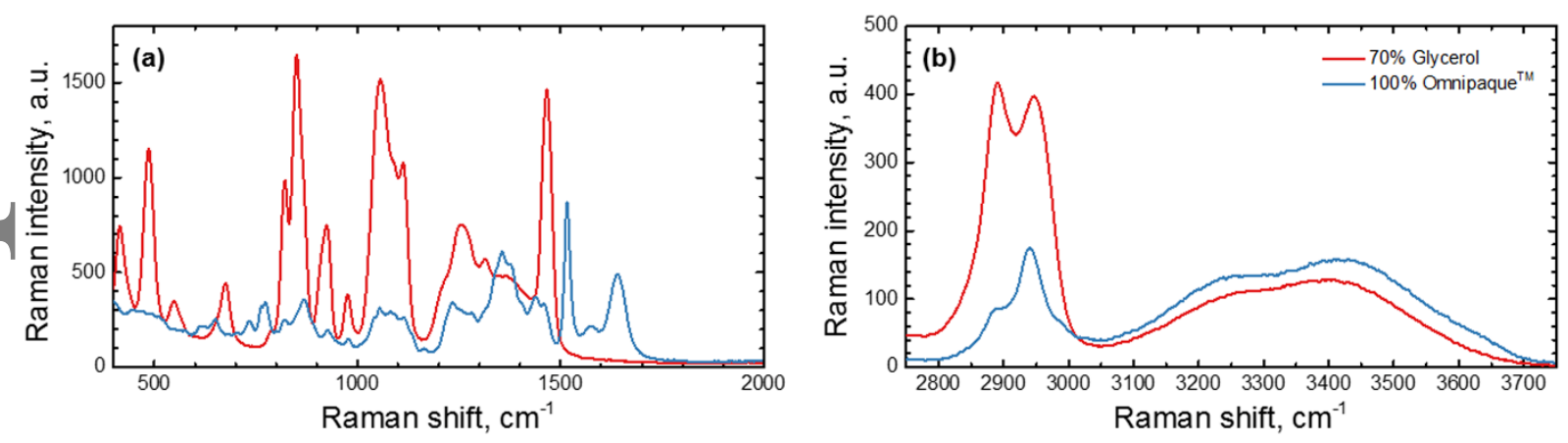

Figure 2. Fingerprint (a) and high wavenumber (b) Raman spectra of $70 \%$ glycerol in water (red line) and 100\% Omnipaque ${ }^{\mathrm{TM}}$ solution (blue line).

For investigation of OCA influence on the hydrogen bound water types, the AUC values for DAA-OH, DDAA-OH, DA-OH and free-OH water types were calculated for different depths. Further, each value has been normalized to the AUC of the Gaussian function centered at $2930 \mathrm{~cm}^{-1}$ for each corresponding depth. Obtained depth-dependent results 
(Raman band ratios) for each water molecule type are summarized in Table 1 (see Supporting Information ).

In general, the sum of all water molecule types, which corresponds to the full water content in the skin, should be equal to $100 \%$. However, due to the averaging of multiple measurements on multiple subjects, the sum of the 4 water molecule types can be different from $100 \%$. For better clarity, the relative changes in the water molecule type's percentage have been calculated for the samples after OCA treatment. Firstly, the ratio values for untreated skin, represented in Table 1 (see Supporting Information), were converted in percentages relative to the full water content. These percentages of each water type for the untreated skin were taken as reference values. Then, the percentage changes after OCA application was found for each water type relative to the control values.

Figure 3 shows relative percentages for DAA-OH, DDAA-OH, DA-OH and free- $\mathrm{OH}$ water types for untreated skin, and skin treated with Omnipaque ${ }^{\mathrm{TM}}$ and glycerol for 30 and 60 min. It is important to notice that the sum of percentages for each water type is less than $100 \%$ for skin after OCA treatment. This is because of displacement of water caused by dehydration during OCA treatment. 

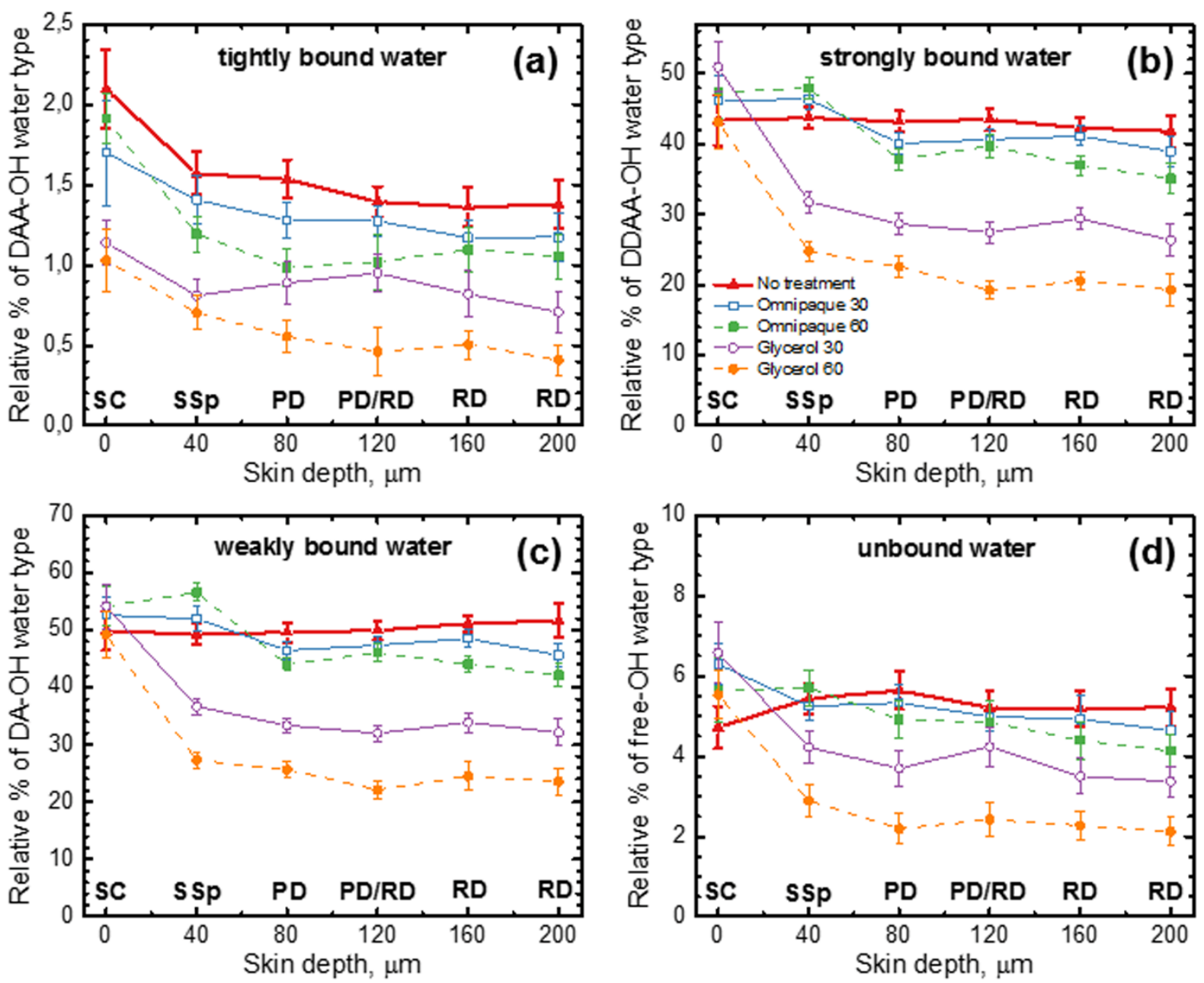

Figure 3. The depth dependent distribution of the relative percentage of $\mathrm{DAA}-\mathrm{OH}(\mathrm{a})$, $\mathrm{DDAA}-\mathrm{OH}(b), \mathrm{DA}-\mathrm{OH}(\mathrm{c})$ and free-OH $(d)$ water types in the untreated skin (thick red line) and in the skin treated with Omnipaque ${ }^{T M}$ for $30 \mathrm{~min} / 60 \mathrm{~min}$ (blue solid line / green dotted line) and in the skin treated with glycerol for $30 \mathrm{~min} / 60 \mathrm{~min}$ (purple solid line / orange dotted line). SC - stratum corneum; SSp - stratum spinosum; PD - papillary dermis; RD reticular dermis.

As shown in Figure 3a, the percentage of tightly hydrogen bound water decreased at all depths after application of both glycerol and Omnipaque ${ }^{\mathrm{TM}}$. However, glycerol has a significantly greater influence on the water content than Omnipaque ${ }^{\mathrm{TM}}$, especially after 60 min of treatment. Comparing to the OCAs influence on the other water types, DAA-OH 
concentration has the least changes after application of OCA (maximum loss was $0.47 \%$ for 60 min glycerol treatment). Also, it is noticeable that for untreated skin, DAA-OH percentage is decreased in depth. Figure $3 b$ shows that DDAA-OH concentration for untreated skin has no significant changes for all investigated depths and takes values about $42-43 \%$. The application of Omnipaque ${ }^{\mathrm{TM}}$ within 30 min slightly affects strongly bound water only at the depths $80-200 \mu \mathrm{m}$. After 60 min of Omnipaque ${ }^{\mathrm{TM}}$ application, it can clearly be seen, that the DDAA-OH percentage started to significantly decrease from $80 \mu \mathrm{m}$ depth. It is also noticeable that the DDAA-OH concentration at the $0-40 \mu \mathrm{m}$ depth for Omnipaque ${ }^{\mathrm{TM}}$-treated skin is greater than for untreated skin. This is maybe due to the presence of Omnipaque ${ }^{\mathrm{TM}}$ in the skin, which is known to penetrate to the $35-40 \mu \mathrm{m}$ depths ${ }^{[42]}$. So, a possible reason for this increase can be the superposition of the skin water content with the water content of Omnipaque $^{\mathrm{TM}}$. Another description lies in a not fully correct normalization on the protein peak at $40 \mu \mathrm{m}$ depth, which represents the stratum spinosum layer. The stratum spinosum layer is protein-deficient in comparison to the $\mathrm{SC}$, which is rich in keratin and to the dermis, which is rich in collagen I, III and elastin ${ }^{[100]}$. The application of glycerol significantly , reduced the DDAA-OH concentration even at $40 \mu \mathrm{m}$ depth. The greatest effect can be observed at the $120 \mu \mathrm{m}$ depth after $60 \mathrm{~min}$ glycerol application, where the concentration decreases from $43.47 \%$ to $19.23 \%$. Figure $3 \mathrm{c}$ also shows that the DA-OH concentration for untreated skin has no significant changes for all investigated depths. However, the DA-OH concentration is slightly higher than DDAA-OH and takes values around 50-51\%. In general, the depth dependent curves for the skin $\mathrm{DA}-\mathrm{OH}$ concentration after $\mathrm{OC}$ have a similar tendency as for DDAA-OH. Omnipaque ${ }^{\mathrm{TM}}$ causes DA-OH to decrease from $80 \mu \mathrm{m}$ depth after 60 min application and glycerol has a higher effect at all depths for both 30 and 60 min of OC. The highest effect can be observed at the $200 \mu \mathrm{m}$ depth after $60 \mathrm{~min}$ glycerol application (concentration loss from $51.60 \%$ to $23.56 \%$ ). Moreover, comparing to the OCAs influence on the other water types, DA-OH concentration shows the maximal changes after 
application of OCA. Figure $3 d$ shows that 30 min treatment with Omnipaque ${ }^{\mathrm{TM}}$ causes just slightly decrease of the free- $\mathrm{OH}$ water content after $80 \mu \mathrm{m}$ depth. Longer application of Omnipaque $^{\mathrm{TM}}$ leads to significant changes in the free- $\mathrm{OH}$ water. Also, it can be seen that the percentage of free- $\mathrm{OH}$ water at the $40 \mu \mathrm{m}$ depth for the samples after $60 \mathrm{~min}$ treatment with Omnipaque $^{\mathrm{TM}}$ is higher than for the untreated skin. As well as for the other types of water, glycerol causes a higher reduction of the free water concentration than Omnipaque ${ }^{\mathrm{TM}}$. The maximal effect can be observed at the $200 \mu \mathrm{m}$ depth after 60 min glycerol application (concentration loss from $5.21 \%$ to $2.12 \%$ ). The values for water types at the surface, presented in Figure 3, are in an excellent agreement to the values published for the entire porcine ear SC ${ }^{[89]}$.

Figure 4 shows percentages for DAA-OH, DDAA-OH, DA-OH and free-OH water types relatively to the total water content for untreated skin, and skin treated with Omnipaque ${ }^{\mathrm{TM}}$ and glycerol for 30 and $60 \mathrm{~min}$. As can be seen, the most concentrated water types at all investigated skin depths for untreated skin are DDAA and DA bound water molecules (more than $90 \%$ ) and the free and DAA bound water are less than $10 \%$, respectively. It is clearly seen that DDAA-OH and DA-OH percentages are significantly reduced at the $80-200 \mu \mathrm{m}$ depths after 30 min (Figure 4b) and 60 min (Figure 4c) Omnipaque ${ }^{\mathrm{TM}}$ treatment and at 40 $200 \mu \mathrm{m}$ depths after $30 \mathrm{~min}$ (Figure 4d) and $60 \mathrm{~min}$ (Figure 4e) glycerol treatment. Also, it can be seen that after application of glycerol (Figure 4d, 4e), the difference between DDAA$\mathrm{OH}$ and DA-OH percentages reduced comparing to the untreated and Omnipaque ${ }^{\mathrm{TM}}$ treated skin. These results show that weakly and strongly hydrogen bound water types are preferentially involved in the OCA-induced water flux in the skin, and thus, are responsible for OC efficiency. 

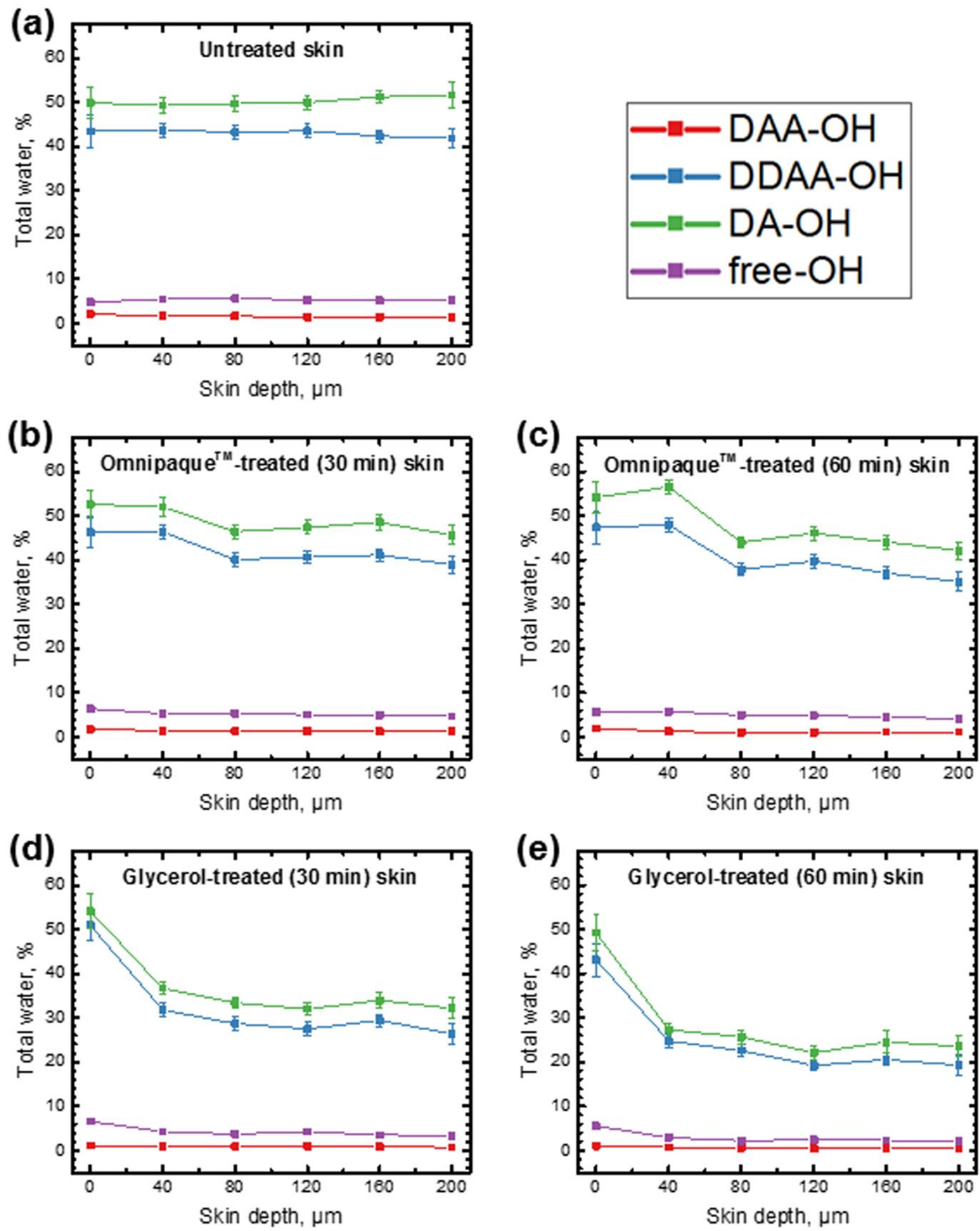

Figure 4. The depth dependent distribution of the percentage of DAA-OH (red line), DDAA$\mathrm{OH}$ (blue line), $\mathrm{DA}-\mathrm{OH}$ (green line) and free-OH (purple line) water types relatively to full water for the untreated skin (a), the skin treated with Omnipaque ${ }^{T M}$ for $30 \mathrm{~min}(b) / 60 \mathrm{~min}(c)$ 
and the skin treated with glycerol for $30 \mathrm{~min}(d) / 60 \mathrm{~min}(e) . S C-$ stratum corneum; SSp stratum spinosum; $P D$ - papillary dermis; $R D$-reticular dermis.
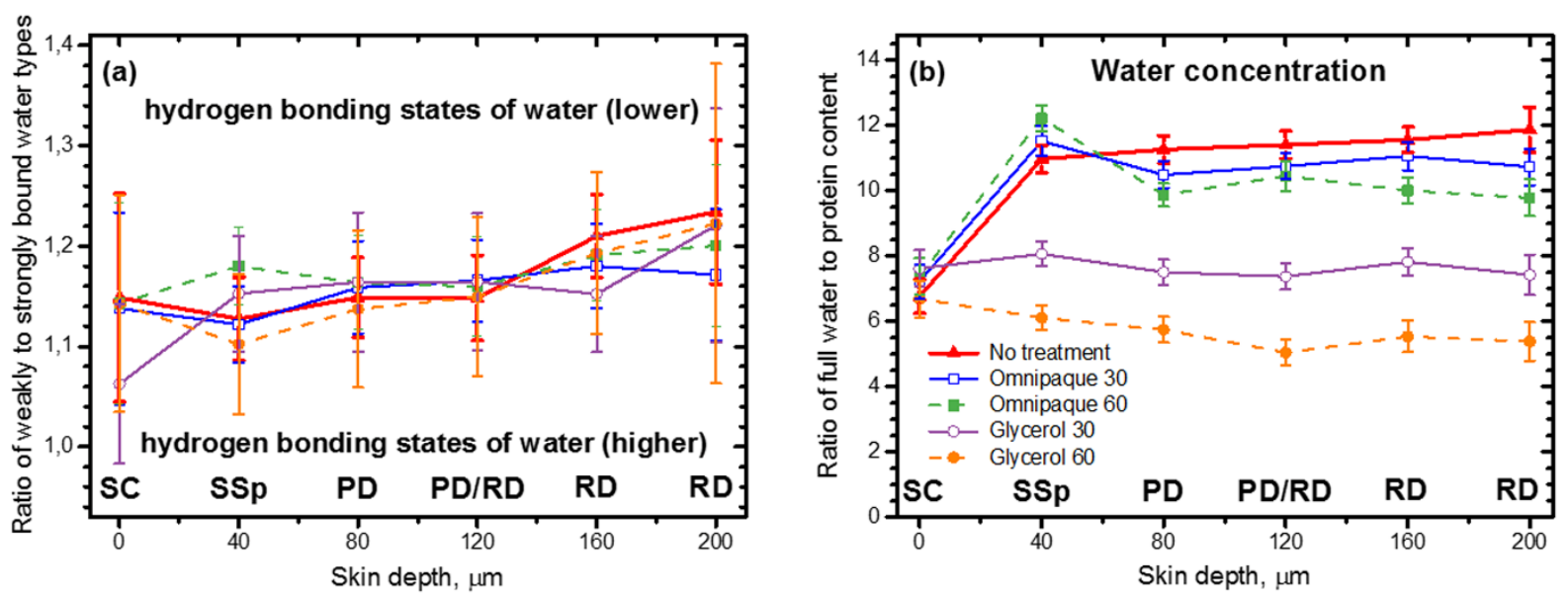

Figure 5. Skin depth profiles of the (a): hydrogen bonding state of water molecules (determined by the weakly bound / strongly bound water molecule types ratio) and (b): total water content (determined by the ratio of full water to proteins content). Thick red line untreated skin; blue solid line / green dotted line - skin treated with Omnipaque ${ }^{T M}$ for 30 min / 60 min; purple solid line / orange dotted line - skin treated with glycerol for 30 min / 60 min. SC - stratum corneum; SSp - stratum spinosum; PD - papillary dermis; $R D$ - reticular dermis.

Figure 5a shows the ratio of weakly bound / strongly bound water molecule types in the skin, which represent the hydrogen bonding state of water molecules ${ }^{[83,101]}$. It can clearly be seen that the application of both OCAs within 30 and 60 min did not affect the hydrogen bonding states of water in the depths $0-200 \mu \mathrm{m}$. Also, to demonstrate the influence of the OCA application on the total skin water content, the depth dependent distribution of the ratio between the total water and proteins has been calculated (see Figure 5b). Quantitative data also presented in Table 1 (see Supporting Information). The total water has been calculated as sum of the AUCs of all 4 hydrogen bound water types normalized to the protein content. As 
shown in Figure 5b, the water content in untreated skin increases from the surface (SC) towards the stratum spinosum (40 $\mu \mathrm{m}$ depth) and reaches its maximum in the depth of 200 $\mu \mathrm{m}$ (1.75-fold difference between superficial layer and $200 \mu \mathrm{m}$ depth,). $30 \mathrm{~min}$ application of Omnipaque $^{\mathrm{TM}}$ caused slight reduction of the water content deeper than $80 \mu \mathrm{m}$ depth. Longer application of Omnipaque ${ }^{\mathrm{TM}}$ caused significant reduction of the total water starting from 80 $\mu \mathrm{m}$. At $0-40 \mu \mathrm{m}$, application of Omnipaque ${ }^{\mathrm{TM}}$ (both 30 and $60 \mathrm{~min}$ ) slightly increase the total water, which is probably due to the presence of OCA (see Figure 2). Also, it can clearly be seen, that the glycerol treatment (both 30 and $60 \mathrm{~min}$ ) induced a strong reduction of water content from $40 \mu \mathrm{m}$ towards the deeper depths. This is due to known dehydration caused by glycerol application ${ }^{[47]}$. In general, the total water content in the skin after 30 and 60 min of Omnipaque $^{\mathrm{TM}}$ treatment reduced to $94 \%$ and $87 \%$ of the initial concentration, respectively, at 80-200 $\mu \mathrm{m}$ depths comparing to untreated skin. Total water content in skin after 30 and 60 min of glycerol treatment reduced to $65 \%$ and $47 \%$ of the initial concentration, respectively, at the same depths comparing to untreated skin.

However, the results for water concentration in the OCA-treated skin can be potentially underestimated, as OCAs are Raman active in the protein range of the skin $\left(2910-2965 \mathrm{~cm}^{-1}\right)$. Based on the spectra presented in Figure $2 b$, this underestimation is higher for glycerol than for Omnipaque ${ }^{\mathrm{TM}}$ (2.66-fold difference between AUC values in the $2910-2965 \mathrm{~cm}^{-1}$ range for $70 \%$ Glycerol and $100 \%$ Omnipaque ${ }^{\mathrm{TM}}$ solutions). Nevertheless, this underestimation is more pronounced close to the surface $(0-40 \mu \mathrm{m})$, where the OCAs have highest concentration (1.48-fold difference between AUC values in the 2910-2965 $\mathrm{cm}^{-1}$ range for $70 \%$ glycerol solution and skin without OCA treatment at the superficial layer $(0 \mu \mathrm{m}$ depth $))$. In deeper skin layers, where the OCAs are also present, it is supposed that the OCA's inherent Raman peak at $2910-2965 \mathrm{~cm}^{-1}$, is significantly lower than the protein peak of the skin, resulting in a much lower underestimation mistake. 
As mentioned above, the most concentrated water types at all skin depths in the untreated skin as well as in skin after OCA treatment are DDAA-OH and DA-OH water molecule types $(>90 \%)$, while the free- $\mathrm{OH}$ and DAA-OH bound water represent the remaining $<10 \%$, which is in accordance to results of Choe et al. for the $\mathrm{SC}^{[83,89]}$.

Previous studies of Omnipaque ${ }^{\mathrm{TM}}$ and glycerol OC efficiency using MPT and CRM showed that glycerol caused greater clearing effect than Omnipaque ${ }^{\mathrm{TM}[40,42]}$. However, Omnipaque ${ }^{\mathrm{TM}}$ OC efficiency was significant and sufficient for skin OC. As far as glycerol causes greater loss of bound and unbound water in skin comparing to Omnipaque ${ }^{\mathrm{TM}}$, it can be suggested that dehydration efficiency directly related with OC efficiency.

It is important to note that increased osmotic pressure caused by glycerol application leads to transition of bound water into unbound water ${ }^{[102,103]}$. Such a transition can also be caused by mechanical pressure ${ }^{[104,105]}$. Thus, both of these factors can lead to local dehydration of the skin. Also, when the glycerol solution penetrates into the skin, glycerol molecules bound tissue's water molecules. This leads to flux between OCA-bound water and skin's water. The molar mass of Omnipaque ${ }^{\mathrm{TM}}$ is 10 times higher than the molar mass of glycerol $(821 \mathrm{~g} / \mathrm{mol}$ and $92 \mathrm{~g} / \mathrm{mol}$, respectively), therefore the diffusion speed for Omnipaque ${ }^{\mathrm{TM}}$ in the skin is much lower than for glycerol. Ventura et al. ${ }^{[106]}$ showed that increase in glycerol concentration up to $40 \%$ caused more intensive water flux in the SC. Carneiro et al. ${ }^{[59]}$ showed that the water content of OCAs has a high impact on the water flux in tissue during the clearing process. Water flux in the system OCA-tissue is minimal or even zero when concentration of water in OCA and concentration of potentially mobile water in tissue are equal. For that condition only glycerol or iohexol molecules are flowing. Thus, it was shown that $60-70 \%$ glycerol solution has the lowest diffusion coefficient in skin, because only glycerol molecules are involved in diffusion process ${ }^{[107]}$. In our case, weakly bound water and unbound water (together approx. 55\% of total water in the skin $(0-200 \mu \mathrm{m})$ ), as most 
mobile water types, are mostly included in the water flux in the skin during the optical clearing process. Strongly bound water, which is approx. $44 \%$ of the total water in the skin $(0-200 \mu \mathrm{m})$, can also take part in this flux, but at lower mobility. These results are in good agreement with the results presented in ${ }^{[107]}$ and are slightly lower that the result obtained for muscle tissues ${ }^{[58,102]}$. This difference can be explained by the skin heterogeneity and different water bounding properties of epidermis and dermis in comparison to other tissues.

It is important to notice, that in vivo application of hyperosmotic agents on the skin causes strong dehydration of the superficial skin layers in a short time period $(10-20 \mathrm{~min}){ }^{[108,109]}$. At these time intervals, the most part of the agents are concentrated in the epidermis. Further penetration of agents into deeper skin layers results in compensatory expansion of microvessels and water diffusion from these microvessels to the dermis and epidermis leading to skin moisturizing at $1-6$ hour time intervals ${ }^{[110]}$. For glycerol, the mechanism behind this is that small hygroscopic glycerol molecules by penetrating into the skin act as a humectant attracting incoming water until it reaches a level of approx. 55\% (w/w), i.e. each molecule of glycerol binds about six molecules of water ${ }^{[111]}$.

The authors believe that Omnipaque ${ }^{\mathrm{TM}}$ can be a promising OCA for future in vivo applications due to its minimal influence on the cutaneous water content. Also, Omnipaque ${ }^{\mathrm{TM}}$ has been certified for the oral and rectal use in medical applications ${ }^{[94]}$. One of the important advantages of Omnipaque $^{\mathrm{TM}}$ is its low viscosity $(11.8 \mathrm{cp})$, allowing Omnipaque ${ }^{\mathrm{TM}}$-based solutions to penetrate into the skin faster and to start the clearing process immediately. Also, compared to glycerol, Omnipaque ${ }^{\mathrm{TM}}$ can provide $\mathrm{OC}$ without noticeable sample shrinkage due to its lower dehydration effect and limited penetration ability ${ }^{[40,42]}$. Moreover, Omnipaque $^{\mathrm{TM}}$ has a low osmolarity $(465 \mathrm{mOsm} / \mathrm{L})$ allowing to avoid significant structural skin deformation ${ }^{[67]}$. Further, application of Omnipaque ${ }^{\mathrm{TM}}$ on skin using chemical enhancers, 
such as a DMSO ${ }^{[79]}$ and oleic acid ${ }^{[112,113]}$ can significantly increase the efficiency of OC and allows to achieve a clearing effect for a deeper depth in a shorter period of time.

\section{Conclusion}

In the present ex vivo study on optical clearing of porcine ear skin using $100 \%$ Omnipaque $^{\mathrm{TM}}$ and $70 \%$ glycerol in water as a OCAs, the changes of full water content and of water molecule types separated by their hydrogen bounding strength (i.e., tightly hydrogen bound, strongly hydrogen bound, weakly hydrogen bound and unbound water types), were investigated using CRM. The reduction in water concentration was calculated as an average decrease in the 40-200 $\mu \mathrm{m}$ depths, where the water shows the lowest concentration gradient, in comparison to untreated skin. It was shown that the application of Omnipaque ${ }^{\mathrm{TM}}$ for $30 \mathrm{~min}$ does not result in significant changes in skin full water profile and only a tendency to reduction has been observed $(\approx 4.4 \%$ reduction $)$. An application of Omnipaque ${ }^{\mathrm{TM}}$ for $60 \mathrm{~min}$ caused loss of the water content starting from $80 \mu \mathrm{m}$ down to $200 \mu \mathrm{m}(\approx 8.3 \%$ reduction $)$, which is related to the significant decrease of tightly bound $(\approx 26.1 \%$ reduction), strongly bound $(\approx 7.9 \%$ reduction) and weakly bound $(\approx 7.5 \%$ reduction) water types in all depths. For the specific depth of $40 \mu \mathrm{m}$, Omnipaque ${ }^{\mathrm{TM}}$-treated skin shows an increase of water concentration on $\approx 5.0 \%$ for $30 \mathrm{~min}$ and $\approx 11.4 \%$ for $60 \mathrm{~min}$ application. The application of $70 \%$ glycerol for $30 \mathrm{~min}$ and $60 \mathrm{~min}$ give rise to highly significant reduction of the full water content $(p<0.005$ for $60 \mathrm{~min}$ application) from $40 \mu \mathrm{m}$ to $200 \mu \mathrm{m}$ skin depth $(\approx 33.1 \%$ and $\approx 51.3 \%$ reduction, respectively). The water types \%-reduction in the skin (average in the depths $40-200 \mu \mathrm{m}$ ) induced by $70 \%$ glycerol (30 $\mathrm{min}$ and $60 \mathrm{~min}$ ) looks as follows: strongly bound $(\approx 33.0 \%$ and $\approx 50.4 \%$ reduction $)$, weakly bound $(\approx 33.2 \%$ and $\approx 51.1 \%$ reduction $)$, tightly bound $(\approx 42.3 \%$ and $\approx 63.6 \%$ reduction $)$, unbound $(\approx 28.7 \%$ and $\approx 55.4 \%$ reduction $)$. 
Thus, the average skin dehydration in the depths $40-200 \mu \mathrm{m}$ induced by the application of glycerol (60 min), glycerol (30 min), Omnipaque ${ }^{\mathrm{TM}}(60 \mathrm{~min})$, and Omnipaque ${ }^{\mathrm{TM}}$ (30 min) is equal to $51.3 \%, 33.1 \%, 8.3 \%$, and $4.4 \%$, respectively. As weakly bound and strongly bound water types together represent approx. $93 \%$ of total water content in the skin, they are mostly involved in the interaction with OCAs. Nevertheless, the most mobile unbound water type, which is approx. 5\% in the skin, is also involved in OCA-induced water flux in the skin.

According to the previous studies of Omnipaque ${ }^{\mathrm{TM}}$ and glycerol $\mathrm{OC}$ efficiency during skin treatment and current studies of OCAs influence on bound and unbound water loss in skin, it can be suggested that the efficiency of OC is directly related with the one of the main mechanisms of OC (dehydration) and depends on the amount of water loss during the OCA treatment. However, prolonged application of OCAs causing strong dehydration can result in negative effects on living tissues. In this way, tradeoff between efficiency of OCAs and their safety should be found for clinical in vivo measurements. The weakly and strongly hydrogen bound water types are preferentially involved in the OCA-induced water flux in the skin, and thus, are responsible for OC efficiency.

Omnipaque $^{\mathrm{TM}}$ is an already approved pharmaceutic substance without any known impact on the skin structure. Based on the obtained results, the authors suggest that Omnipaque ${ }^{\mathrm{TM}}$ is an effective and promising OCA due to its sufficient clearing effect with limited penetration depth into the tissue, low impact on the skin physiology and a safe application in medicine.

\section{Supporting Information}

Table 1. Depth-dependent AUC values of DAA-OH, DDAA-OH, DA-OH, free-OH water types and full water content normalized to the protein peak. Mean values $\pm \mathrm{SD}$. “*”represent the significant differences between untreated and OCA-treated skin with $p<0.005$. 
DAA-OH water band to protein band ratio (tightly hydrogen bound water)

\begin{tabular}{l|l|l|l|l|l}
\hline Depth, & Untreated & Omnipaque & Omnipaque & TM, & Glycerol, \\
$\mu \mathrm{m}$ & $30 \mathrm{~min}$ & $60 \mathrm{~min}$ & $30 \mathrm{~min}$ & $60 \mathrm{~min}$ \\
\hline 0 & $0.14 \pm 0.02$ & $0.11 \pm 0.02$ & $0.13 \pm 0.01$ & $0.08 \pm 0.01$ & $0.07 \pm 0.01$ \\
\hline 40 & $0.17 \pm 0.01$ & $0.15 \pm 0.02$ & $0.13 \pm 0.01$ & $0.09 \pm 0.01^{*}$ & $0.08 \pm 0.01^{*}$ \\
\hline 80 & $0.17 \pm 0.01$ & $0.14 \pm 0.01$ & $0.11 \pm 0.01$ & $0.10 \pm 0.01$ & $0.06 \pm 0.01^{*}$ \\
\hline 120 & $0.16 \pm 0.01$ & $0.14 \pm 0.01$ & $0.11 \pm 0.02$ & $0.11 \pm 0.01$ & $0.05 \pm 0.02^{*}$ \\
\hline 160 & $0.16 \pm 0.01$ & $0.13 \pm 0.01$ & $0.12 \pm 0.01$ & $0.09 \pm 0.01^{*}$ & $0.06 \pm 0.01^{*}$ \\
\hline 200 & $0.16 \pm 0.02$ & $0.14 \pm 0.02$ & $0.12 \pm 0.01$ & $0.08 \pm 0.01^{*}$ & $0.05 \pm 0.01^{*}$ \\
\hline
\end{tabular}

DDAA-OH water band to protein band ratio (strongly hydrogen bound water)

\begin{tabular}{l|l|l|l|l|l}
\hline Depth, & Untreated & Omnipaque & Omnipaque & \\
$\mu \mathrm{m}$ & $30 \mathrm{~min}$ & $60 \mathrm{~min}$ & $30 \mathrm{~min}$ & $60 \mathrm{~min}$ \\
\hline 0 & $2.93 \pm 0.24$ & $3.12 \pm 0.21$ & $3.20 \pm 0.24$ & $3.44 \pm 0.25$ & $2.91 \pm 0.24$ \\
\hline 40 & $4.79 \pm 0.19$ & $5.08 \pm 0.14$ & $5.26 \pm 0.18$ & $3.49 \pm 0.17^{*}$ & $2.71 \pm 0.18^{*}$ \\
\hline 80 & $4.86 \pm 0.14$ & $4.51 \pm 0.18$ & $4.25 \pm 0.18$ & $3.23 \pm 0.16^{*}$ & $2.54 \pm 0.15^{*}$ \\
\hline 120 & $4.95 \pm 0.2$ & $4.63 \pm 0.14$ & $4.53 \pm 0.17$ & $3.13 \pm 0.19^{*}$ & $2.19 \pm 0.16^{*}$ \\
\hline 160 & $4.88 \pm 0.18$ & $4.75 \pm 0.17$ & $4.27 \pm 0.17$ & $3.40 \pm 0.16^{*}$ & $2.37 \pm 0.16^{*}$ \\
\hline 200 & $4.96 \pm 0.29$ & $4.62 \pm 0.25$ & $4.16 \pm 0.24$ & $3.12 \pm 0.27^{*}$ & $2.29 \pm 0.25^{*}$ \\
\hline
\end{tabular}


DA-OH water band to protein band ratio (weakly hydrogen bound water)

\begin{tabular}{l|l|l|l|l|l}
\hline Depth, & Untreated & Omnipaque & Omnipaque & \\
$\mu \mathrm{m}$ & $30 \mathrm{~min}$ & $60 \mathrm{~min}$ & $30 \mathrm{~min}$ & $60 \mathrm{~min}$ \\
\hline 0 & $3.37 \pm 0.24$ & $3.55 \pm 0.24$ & $3.66 \pm 0.24$ & $3.65 \pm 0.27$ & $3.33 \pm 0.27$ \\
\hline 40 & $5.40 \pm 0.23$ & $5.70 \pm 0.25$ & $6.20 \pm 0.19$ & $4.02 \pm 0.18^{*}$ & $2.99 \pm 0.17^{*}$ \\
\hline 80 & $5.59 \pm 0.21$ & $5.23 \pm 0.17$ & $4.95 \pm 0.14$ & $3.76 \pm 0.17^{*}$ & $2.89 \pm 0.16^{*}$ \\
\hline 120 & $5.69 \pm 0.2$ & $5.0 \pm 0.2$ & $5.25 \pm 0.17$ & $3.65 \pm 0.17^{*}$ & $2.52 \pm 0.2^{*}$ \\
\hline 160 & $5.91 \pm 0.17$ & $5.61 \pm 0.2$ & $5.09 \pm 0.21$ & $3.91 \pm 0.20^{*}$ & $2.93 \pm 0.26^{*}$ \\
\hline 200 & $6.12 \pm 0.38$ & $5.1 \pm 0.27$ & $5.00 \pm 0.25$ & $3.81 \pm 0.30^{*}$ & $2.79 \pm 0.25^{*}$ \\
\hline
\end{tabular}

Free- $\mathrm{OH}$ water band to protein band ratio (unbound water)

\begin{tabular}{l|l|l|l|l|l}
\hline Depth, & Untreated & Omnipaque & Omnipaque & TM, & Glycerol, \\
$\mu \mathrm{m}$ & $30 \mathrm{~min}$ & $60 \mathrm{~min}$ & $30 \mathrm{~min}$ & $60 \mathrm{~min}$ \\
\hline 0 & $0.32 \pm 0.04$ & $0.42 \pm 0.04$ & $0.38 \pm 0.05$ & $0.44 \pm 0.05$ & $0.37 \pm 0.04$ \\
\hline 40 & $0.59 \pm 0.05$ & $0.57 \pm 0.04$ & $0.62 \pm 0.05$ & $0.46 \pm 0.04^{*}$ & $0.32 \pm 0.04^{*}$ \\
\hline 80 & $0.63 \pm 0.05$ & $0.60 \pm 0.04$ & $0.55 \pm 0.04$ & $0.51 \pm 0.04^{*}$ & $0.25 \pm 0.04^{*}$ \\
\hline 120 & $0.59 \pm 0.05$ & $0.57 \pm 0.04$ & $0.55 \pm 0.06$ & $0.48 \pm 0.05$ & $0.27 \pm 0.05^{*}$ \\
\hline 160 & $0.60 \pm 0.05$ & $0.57 \pm 0.07$ & $0.50 \pm 0.05$ & $0.40 \pm 0.05^{*}$ & $0.26 \pm 0.04^{*}$ \\
\hline 200 & $0.62 \pm 0.05$ & $0.55 \pm 0.05$ & $0.49 \pm 0.05$ & $0.40 \pm 0.04^{*}$ & $0.25 \pm 0.04^{*}$ \\
\hline
\end{tabular}


Full water content to protein band ration

\begin{tabular}{l|l|l|l|l|l}
\hline Depth, & Untreated & Omnipaque & Omnipaque & \\
$\mu \mathrm{m}$ & $30 \mathrm{~min}$ & $60 \mathrm{~min}$ & $30 \mathrm{~min}$ & $60 \mathrm{~min}$ \\
\hline 0 & $6.76 \pm 0.59$ & $7.22 \pm 0.5$ & $7.37 \pm 0.58$ & $7.62 \pm 0.6$ & $6.68 \pm 0.62$ \\
\hline 40 & $10.97 \pm 0.46$ & $11.52 \pm 0.49$ & $12.22 \pm 0.43$ & $8.06 \pm 0.41^{*}$ & $6.10 \pm 0.36^{*}$ \\
\hline 80 & $11.26 \pm 0.45$ & $10.49 \pm 0.45$ & $9.87 \pm 0.36$ & $7.50 \pm 0.41^{*}$ & $5.74 \pm 0.41$ \\
\hline 120 & $11.40 \pm 0.46$ & $10.75 \pm 0.42$ & $10.45 \pm 0.46$ & $7.37 \pm 0.42^{*}$ & $5.04 \pm 0.44^{*}$ \\
\hline 160 & $11.55 \pm 0.43$ & $11.06 \pm 0.47$ & $10.00 \pm 0.44$ & $7.82 \pm 0.41^{*}$ & $5.53 \pm 0.5^{*}$ \\
\hline 200 & $11.87 \pm 0.74$ & $10.72 \pm 0.57$ & $9.78 \pm 0.58$ & $7.42 \pm 0.6^{*}$ & $5.38 \pm 0.58^{*}$ \\
\hline
\end{tabular}

\section{Acknowledgements}

The study was supported by the German Foundation Centre Essen, Foundation for Skin Physiology (T335). Anton Sdobnov is thankful to the Research Program of Saratov State University for financial support of visiting Charité-Universitätsmedizin Berlin. Valery Tuchin was supported by the RF MES grant 17.1223.2017/AP and the RF Governmental grant 14.W03.31.0023.

\section{References}

[1] M. Yokota, Y. Tokudome Skin Pharmacol Physiol. 2016, 29, 231-242.

[2] E. Proksch, J. M. Brandner, J. M. Jensen Exp Dermatol. 2008, 17, 1063-1072.

[3] J. van Smeden, M. Janssens, E. C. Kaye, P. J. Caspers, A. P. Lavrijsen, R. J. Vreeken, J. A. Bouwstra Exp Dermatol. 2014, 23, 45-52.

[4] R. J. Richters, D. Falcone, N. E. Uzunbajakava, B. Varghese, P. J. Caspers, G. J. Puppels, P. E. van Erp, P. C. van de Kerkhof Skin Pharmacol Physiol. 2017, 30, 1-12. 
[5] E. N. Tessema, T. Gebre-Mariam, R. H. H. Neubert, J. Wohlrab Skin Pharmacol Physiol. 2017, 30, 115-138.

[6] P. M. Elias J Invest Dermatol. 2012, 132, 2131-2133.

[7] L. Norlen Skin Pharmacol Physiol. 2013, 26, 213-216.

[8] C. L. Fischer, D. R. Blanchette, K. A. Brogden, D. V. Dawson, D. R. Drake, J. R. Hill, P. W. Wertz Biochim Biophys Acta. 2014, 1841, 319-322.

[9] J. van Smeden, M. Janssens, G. S. Gooris, J. A. Bouwstra Biochim Biophys Acta. 2014, 1841, 295-313.

[10] C. Choe, J. Lademann, M. E. Darvin Analyst. 2016, 141, 1981-1987.

[11] A. F. Fercher J Biomed Opt. 1996, 1, 157-173.

[12] T. Gambichler, A. Pljakic, L. Schmitz Clin Cosmet Investig Dermatol. 2015, 8, 345-354.

[13] C. Choe, J. Lademann, M. E. Darvin Skin Pharmacol Physiol. 2015, 28, 318-330.

[14] R. Vyumvuhore, A. Tfayli, O. Piot, M. Le Guillou, N. Guichard, M. Manfait, A. BailletGuffroy J Biomed Opt. 2014, 19, 111603.

[15] C. Krafft, J. Popp Anal Bioanal Chem. 2015, 407, 699-717.

[16] M. E. Darvin, I. Gersonde, H. Albrecht, S. A. Gonchukov, W. Sterry, J. Lademann Laser Physics. 2005, 15, 295-299.

[17] M. Rajadhyaksha, M. Grossman, D. Esterowitz, R. H. Webb, R. R. Anderson J Invest Dermatol. 1995, 104, 946-952.

[18] K. Konig, I. Riemann J Biomed Opt. 2003, 8, 432-439.

[19] M. Balu, H. Mikami, J. Hou, E. O. Potma, B. J. Tromberg Biomed Opt Express. 2016, 7, 4375-4387.

[20] H. G. Breunig, M. Weinigel, R. Buckle, M. Kellner-Hofer, J. Lademann, M. E. Darvin, W. Sterry, K. Konig Laser Physics Letters. 2013, 10, 025604.

[21] M. Weinigel, H. G. Breunig, M. Kellner-Hofer, R. Buckle, M. E. Darvin, M. Klemp, J. Lademann, K. Konig Laser Physics Letters. 2014, 11, 055601.

[22] M. Roustit, C. Millet, S. Blaise, B. Dufournet, J. L. Cracowski Microvasc Res. 2010, 80, 505-511.

[23] E. Gratton Science. 2011, 331, 1016-1017.

[24] V. V. Tuchin, Tissue Optics: Light Scattering Methods and Instruments for Medical diagnosis, SPIE Press, Bellingham, WA USA, 2015.

[25] A. Y. Sdobnov, M. E. Darvin, E. A. Genina, A. N. Bashkatov, J. Lademann, V. V. Tuchin Spectrochim Acta A Mol Biomol Spectrosc. 2018, 197, 216-229.

[26] D. Zhu, K. V. Larin, Q. Luo, V. V. Tuchin Laser Photon Rev. 2013, 7, 732-757.

[27] D. S. Richardson, J. W. Lichtman Cell. 2015, 162, 246-257.

[28] E. A. Susaki, H. R. Ueda Cell Chem Biol. 2016, 23, 137-157.

[29] L. Silvestri, I. Costantini, L. Sacconi, F. S. Pavone J Biomed Opt. 2016, 21, 081205.

[30] T. Yu, Y. Qi, H. Gong, Q. Luo, D. Zhu J Biophotonics. 2018, 11.

[31] R. Cai, C. Pan, A. Ghasemigharagoz, M. Todorov, B. Foerstera, S. Zhao, H. Bhatia, L. Mrowka, D. Theodorou, M. Rempfler, A. Xavier, B. T Kress, C. Benakis, A. Liesz, B. Menze, M. Kerschensteiner, M. Nedergaard, A. Erturk, Panoptic vDISCO imaging reveals neuronal connectivity, remote trauma effects and meningeal vessels in intact transparent mice, 2018, https://doi.org/10.1101/374785.

[32] J. Jiang, M. Boese, P. Turner, R. K. Wang J Biomed Opt. 2008, 13, 021105.

[33] K. V. Larin, V. V. Tuchin Quantum Electronics. 2008, 38, 551-556.

[34] D. K. Tuchina, R. Shi, A. N. Bashkatov, E. A. Genina, D. Zhu, Q. Luo, V. V. Tuchin J Biophotonics. 2015, 8, 332-346.

[35] A. K. Bui, R. A. McClure, J. Chang, C. Stoianovici, J. Hirshburg, A. T. Yeh, B. Choi Lasers Surg Med. 2009, 41, 142-148.

[36] H. Hama, H. Kurokawa, H. Kawano, R. Ando, T. Shimogori, H. Noda, K. Fukami, A. Sakaue-Sawano, A. Miyawaki Nat Neurosci. 2011, 14, 1481-1488. 
[37] H. Hama, H. Hioki, K. Namiki, T. Hoshida, H. Kurokawa, F. Ishidate, T. Kaneko, T. Akagi, T. Saito, T. Saido, A. Miyawaki Nat Neurosci. 2015, 18, 1518-1529.

[38] V. V. Tuchin, X. Xu, R. K. Wang Appl Opt. 2002, 41, 258-271.

[39] R. Cicchi, D. Sampson, D. Massi, F. Pavone Opt Express. 2005, 13, 2337-2344.

[40] A. Sdobnov, M. E. Darvin, J. Lademann, V. Tuchin J Biophotonics. 2017, 10, 1115-1123. [41] M. V. Schulmerich, J. H. Cole, K. A. Dooley, M. D. Morris, J. M. Kreider, S. A. Goldstein J Biomed Opt. 2008, 13, 021108.

[42] A. Sdobnov, V. Tuchin, J. Lademann, M. Darvin Journal of Physics D: Applied Physics. 2017, 50, 285401.

[43] M. E. Darvin, J. Schleusener, F. Parenz, O. Seidel, C. Krafft, J. Popp, J. Lademann Analyst. 2018, 143, 4990-4999.

[44] P. Wan, J. Zhu, T. Yu, D. Zhu SPIE BiOS. 2018, 10481, 10481-104811I.

[45] E. A. Genina, A. N. Bashkatov, V. V. Tuchin Expert Rev Med Devices. 2010, 7, 825-842.

[46] V. V. Tuchin, Optical Clearing of Tissues and Blood, SPIE Press, Bellingham, WA USA, 2006.

[47] C. G. Rylander, O. F. Stumpp, T. E. Milner, N. J. Kemp, J. M. Mendenhall, K. R. Diller, A. J. Welch J Biomed Opt. 2006, 11, 041117.

[48] T. Yu, X. Wen, V. V. Tuchin, Q. Luo, D. Zhu J Biomed Opt. 2011, 16, 095002.

[49] J. Hirshburg, B. Choi, J. S. Nelson, A. T. Yeh J Biomed Opt. 2006, 11, 040501.

[50] J. M. Hirshburg, K. M. Ravikumar, W. Hwang, A. T. Yeh J Biomed Opt. 2010, 15, 055002.

[51] A. T. Yeh, J. Hirshburg J Biomed Opt. 2006, 11, 014003.

[52] R. K. K. Wang, X. Q. Xu, Y. H. He, J. B. Elder Ieee Journal of Selected Topics in Quantum Electronics. 2003, 9, 234-242.

[53] A. Erturk, K. Becker, N. Jahrling, C. P. Mauch, C. D. Hojer, J. G. Egen, F. Hellal, F. Bradke, M. Sheng, H. U. Dodt Nat Protoc. 2012, 7, 1983-1995.

[54] M. Egawa, M. Yanai, N. Maruyama, Y. Fukaya, T. Hirao Appl Spectrosc. 2015, 69, 481487.

[55] E. Boireau-Adamezyk, A. Baillet-Guffroy, G. N. Stamatas J Invest Dermatol. 2014, 134, 2046-2049.

[56] M. Akdeniz, H. Boeing, U. Muller-Werdan, V. Aykac, A. Steffen, M. Schell, U. BlumePeytavi, J. Kottner Skin Pharmacol Physiol. 2018, 31, 155-162.

[57] R. Shi, L. Guo, C. Zhang, W. Feng, P. Li, Z. Ding, D. Zhu J Biophotonics. 2017, 10, 887-895.

[58] L. M. Oliveira, M. I. Carvalho, E. M. Nogueira, V. V. Tuchin J Biophotonics. 2018, 11.

[59] I. Carneiro, S. Carvalho, R. Henrique, L. Oliveira, V. V. Tuchin J Biomed Opt. 2017, 22, $1-10$.

[60] P. Behm, M. Hashemi, S. Hoppe, S. Wessel, R. Hagens, S. Jaspers, H. Wenck, M. Rubhausen Aip Advances. 2017, 7, 8.

[61] D. Zhu, B. Choi, E. Genina, V. V. Tuchin J Biomed Opt. 2016, 21, 081201.

[62] L. Pires, V. Demidov, I. A. Vitkin, V. Bagnato, C. Kurachi, B. C. Wilson J Biomed Opt. 2016, 21, 081210.

[63] J. Ma, B. Chen, Y. Zhang, D. Li, Z. L. Xing Lasers Med Sci. 2017, 32, 1321-1335.

[64] C. H. Chang, E. M. Myers, M. J. Kennelly, N. M. Fried J Biomed Opt. 2017, 22, 18002.

[65] C. Zhang, W. Feng, Y. Zhao, T. Yu, P. Li, T. Xu, Q. Luo, D. Zhu Theranostics. 2018, 8, 2696-2708.

[66] X. Wen, Z. Mao, Z. Han, V. V. Tuchin, D. Zhu J Biophotonics. 2010, 3, 44-52.

[67] A. Bykov, T. Hautala, M. Kinnunen, A. Popov, S. Karhula, S. Saarakkala, M. T. Nieminen, V. Tuchin, I. Meglinski J Biophotonics. 2016, 9, 270-275.

[68] C. P. Fleming, J. Eckert, E. F. Halpern, J. A. Gardecki, G. J. Tearney Biomed Opt Express. 2013, 4, 1269-1284. 
[69] P. A. Timoshina, A. B. Bucharskaya, D. A. Alexandrov, V. V. Tuchin Journal of Biomedical Photonics \& Engineering. 2017, 3, 020301.

[70] C. Kallaway, L. M. Almond, H. Barr, J. Wood, J. Hutchings, C. Kendall, N. Stone Photodiagnosis Photodyn Ther. 2013, 10, 207-219.

[71] C. Choe, J. Schleusener, J. Lademann, M. E. Darvin Mech Ageing Dev. 2018, 172, 6-12.

[72] H. Lui, J. Zhao, D. McLean, H. Zeng Cancer Res. 2012, 72, 2491-2500.

[73] M. E. Darvin, M. C. Meinke, W. Sterry, J. Lademann J Biomed Opt. 2013, 18, 61230.

[74] M. E. Darvin, W. Sterry, J. Lademann, T. Vergou Molecules. 2011, 16, 10491-10506.

[75] L. Miloudi, F. Bonnier, A. Tfayli, F. Yvergnaux, H. J. Byrne, I. Chourpa, E. Munnier J Biophotonics. 2018, 11, e201700221.

[76] C. Choe, J. Schleusener, J. Lademann, M. E. Darvin Scientific Reports. 2017, 7, 15900.

[77] C. Souza, P. Maia Campos, S. Schanzer, S. Albrecht, S. B. Lohan, J. Lademann, M. E. Darvin, M. C. Meinke Skin Pharmacol Physiol. 2017, 30, 81-89.

[78] S. Mujica Ascencio, C. Choe, M. C. Meinke, R. H. Muller, G. V. Maksimov, W. WiggerAlberti, J. Lademann, M. E. Darvin Eur J Pharm Biopharm. 2016, 104, 51-58.

[79] P. J. Caspers, A. C. Williams, E. A. Carter, H. G. Edwards, B. W. Barry, H. A. Bruining, G. J. Puppels Pharm Res. 2002, 19, 1577-1580.

[80] P. J. Caspers, G. W. Lucassen, E. A. Carter, H. A. Bruining, G. J. Puppels J Invest Dermatol. 2001, 116, 434-442.

[81] N. Nakagawa, M. Matsumoto, S. Sakai Skin Res Technol. 2010, 16, 137-141.

[82] R. Vyumvuhore, A. Tfayli, H. Duplan, A. Delalleau, M. Manfait, A. Baillet-Guffroy Analyst. 2013, 138, 4103-4111.

[83] C. Choe, J. Lademann, M. E. Darvin Analyst. 2016, 141, 6329-6337.

[84] Q. Sun Vibrational Spectroscopy. 2009, 51, 213-217.

[85] T. P. Sullivan, W. H. Eaglstein, S. C. Davis, P. Mertz Wound Repair Regen. 2001, 9, 6676.

[86] M. E. Darvin, H. Richter, Y. J. Zhu, M. C. Meinke, F. Knorr, S. A. Gonchukov, K. Koenig, J. Lademann Quantum Electronics. 2014, 44, 646-651.

[87] S. Mangelsdorf, T. Vergou, W. Sterry, J. Lademann, A. Patzelt Skin Res Technol. 2014, 20, 147-154.

[88] S. Debeer, J. B. Le Luduec, D. Kaiserlian, P. Laurent, J. F. Nicolas, B. Dubois, J. Kanitakis Eur J Dermatol. 2013, 23, 456-466.

[89] C. Choe, J. Schleusener, J. Lademann, M. E. Darvin J Biophotonics. 2018, 11, e201700355.

[90] M. H. Khan, B. Choi, S. Chess, M. K. K, J. McCullough, J. S. Nelson Lasers Surg Med. 2004, 34, 83-85.

[91] X. Wen, S. L. Jacques, V. V. Tuchin, D. Zhu J Biomed Opt. 2012, 17, 066022.

[92] T. Son, B. Jung Skin Res Technol. 2015, 21, 327-332.

[93] A. Glycerine Producers, Physical properties of glycerine and its solutions, Glycerine Producers' Association, New York, 1963.

[94] https://www.accessdata.fda.gov/drugsatfda_docs/nda/pre96/018956s28_omnipaque toc.cfm, 2018, U. S. Food and Drug Administration, City, 2018.

[95] C. Robert, M. Bonnet, S. Marques, M. Numa, O. Doucet Skin Pharmacol Physiol. 2015, 28, 196-204.

[96] M. E. Darvin, I. Gersonde, H. Albrecht, L. Zastrow, W. Sterry, J. Lademann Laser Physics Letters. 2007, 4, 318-321.

[97] M. Y. Akhalaya, G. V. Maksimov, A. B. Rubin, J. Lademann, M. E. Darvin Ageing Res Rev. 2014, 16, 1-11.

[98] J. Schleusener, V. Carrer, A. Patzelt, J. Lademann, M. E. Darvin Laser Physics Letters. 2017, 14, 125601.

[99] A. Mudalige, J. E. Pemberton Vibrational Spectroscopy. 2007, 45, 27-35. 
[100] E. A. Shirshin, Y. I. Gurfinkel, A. V. Priezzhev, V. V. Fadeev, J. Lademann, M. E. Darvin Sci Rep. 2017, 7, 1171.

[101] Y. Maeda, H. Kitano Spectrochimica Acta Part A: Molecular and Biomolecular Spectroscopy. 1995, 51, 2433-2446.

[102] S. Carvalho, N. Gueiral, E. Nogueira, R. Henrique, L. Oliveira, V. V. Tuchin J Biomed Opt. 2017, 22, 91506.

[103] B. Schulz, D. Chan, J. Backstrom, M. Rubhausen Thin Solid Films. 2004, 455, 731-734.

[104] A. A. Gurjarpadhye, W. C. Vogt, Y. Liu, C. G. Rylander Int J Biomed Imaging. 2011, 2011, 817250 .

[105] C. X. Li, J. Y. Jiang, K. X. Xu Journal of Innovative Optical Health Sciences. 2013, 6, 9.

[106] S. A. Ventura, G. B. Kasting Int J Cosmet Sci. 2017, 39, 165-178.

[107] V. D. Genin, D. K. Tuchina, A. J. Sadeq, E. A. Genina, V. V. Tuchin, A. N. Bashkatov J Biomed Photon Eng. 2016, 2, 010303.

[108] S. R. Utz, V. V. Tuchin, E. M. Galkina Vestnik dermatologii i venerologii. 2015, 4, 6068.

[109] A. S. Kolesnikov, E. A. Kolesnikova, K. N. Kolesnikova, D. K. Tuchina, A. P. Popov, A. A. Skaptsov, M. M. Nazarov, A. P. Shkurinov, A. G. Terentyuk, V. V. Tuchin Physics of Wave Phenomena. 2014, 22, 169-176.

[110] Bioengineering of the Skin. Skin Imaging and Analysis, Informa Healthcare, New York, 2007.

[111] J. W. Wiechers, J. C. Dederen, A. V. Rawlings in Moisturization Mechanisms: Internal Occlusion by Orthorhombic Lipid Phase Stabilizers A Novel Mechanism of Skin Moisturization, Vol. (Eds.: A. V. R. Rawlings, J. Leyden), Informa Healthcare, Taylor \& Francis Group, New York, 2009, pp.309-321.

[112] J. Jiang, R. K. Wang Phys Med Biol. 2004, 49, 5283-5294.

[113] J. Y. Jiang, R. K. Wang J X-Ray Sci Technol. 2005, g13, 149-159.

\section{Graphical abstract}

In this study, the influence of optical clearing agents (70\% glycerol and $100 \%$ Omnipaque $^{\mathrm{TM}}$ solutions) on the hydrogen bound water molecule types in porcine skin has been investigated ex vivo using confocal Raman microscopy. The changes in concentration of weakly bound, strongly bound, tightly bound and unbound water types have been microscopically analyzed down to the depth of $200 \mu \mathrm{m}$ using Gaussian function-based deconvolution. 


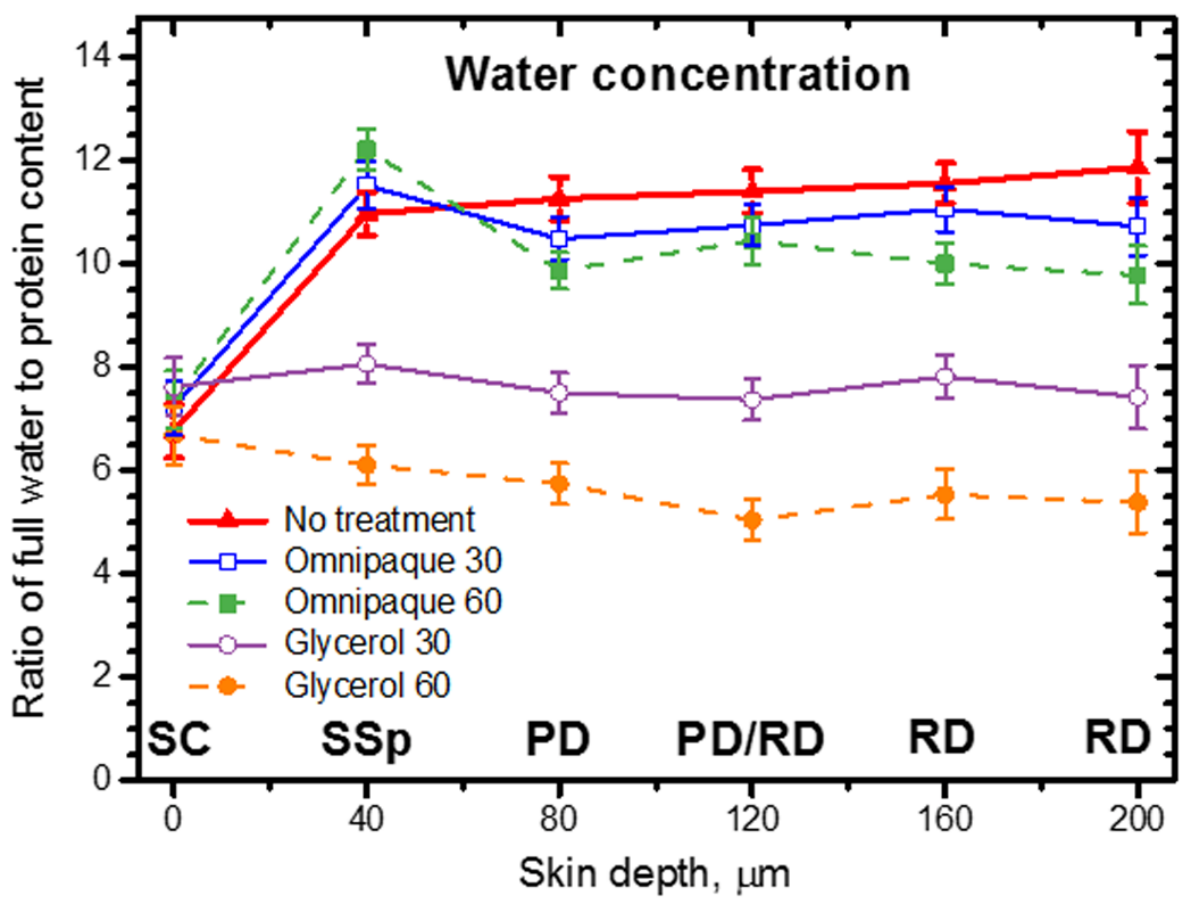

This article is protected by copyright. All rights reserved. 